\title{
Pode-se falar, nestes anos 2000, de um modelo latino-americano de cidade ou metrópole? Ponto de vista de uma europeia
}

\author{
Is it possible to talk, in the 21st century, of a Latin American \\ model of city or metropolis? A European's point of view
}

Hélène Rivière d'Arc

\section{Resumo}

A partir da indagação sobre o que se pode entender por cidade neoliberal na América Latina nos anos 1990, o artigo apresenta algumas reflexões sobre eventos que pontuaram a história das cidades, identificando quais são as categorias do passado que esclarecem as atualmente em uso nas investigações e, principalmente, as referentes aos sistemas que organizam um domínio particular: a metrópole na América Latina. Como em qualquer parte, a cidade neoliberal é a cidade financeirizada, onde a construção sob todas as suas formas, em todo o território urbano que faz agora parte dos ativos bancários, conduz à privatização dos antigos serviços e à difusão de novos serviços quase exclusivamente privados. Esta definição abarca praticamente todas as cidades da América Latina, grandes e médias, e até mesmo cidades tão diversas quanto São Paulo e Tegucigalpa. 0 texto destaca seis paradigmas de análise, orientadores de importantes trabalhos de pesquisa sobre o processo de urbanização latino-americano, permitindo analisar a simultaneidade e a similaridade desse processo em diferentes países e em diferentes períodos de tempo.

Palavras-chave: neoliberalismo; cidade latino-americana; urbanização.

\begin{abstract}
The paper initially asks what can be understood by neoliberal city in Latin America in the 1990s and presents some reflections on events that have marked the history of cities. It identifies the categories of the past that clarify the ones that are currently in use in investigations, mainly those referring to systems that organize a specific domain: the metropolis in Latin America. As in anywhere else, the neoliberal city is the financialized city, where construction, in all its forms, in the entire urban territory which is now part of bank assets, leads to the privatization of old services and to the diffusion of new services, which are almost exclusively private. This definition encompasses practically all the cities of Latin America, large and medium-sized, and even diverse cities like São Paulo and Tegucigalpa. The text highlights six analysis paradigms that have guided important research studies on the Latin American urbanization process, allowing to analyze the simultaneity and the similarity of this process in different countries and in different periods of time.
\end{abstract}

Keywords: neoliberalism; Latin American city; urbanization. 
Na Europa, a existência de um modelo de cidade latino-americana é quase uma evidência, mas inclui muitos clichês que não são válidos para todo lugar. Cultura e culturas políticas são os campos que sustentam esse modelo, elas mesmas construídas em imagem e em memória que as sociedades têm de sua própria extensão temporal e na contemporaneidade em escalas urbanas e/ou nacionais dos acontecimentos que "presentificam o passado".

Assim é possível prosseguir nesta mesma linha de análise para pensar um modelo da cidade latino-americana que não seja apenas redutível à cultura e ao patrimônio, mas também ao impacto da mundialização pela imposição do neoliberalismo econômico.

Parece que às vezes a história se repete. Na América Latina, o esgotamento do modelo liberal nos anos 1930 dava lugar, sob o impacto da revolução mexicana e o surgimento dos movimentos indígenas, ao desejo de restauração nacional e ao retorno às raízes no âmbito de uma modernidade universal. É assim que os arquitetos viam o contexto no qual se construía a cidade (Rivière D’Arc e Schneier, 1993). À cidade neoliberal que emergiu nos anos 1990, os Estados que procuravam reinstaurar sua história nos anos 2000 não procuram, eles também, dar uma mudança de orientação mais social, mais original, mais nacional e latino-americana por meio das políticas urbanas e de suas projeções?

Já é possível responder a essa pergunta não dizendo que a história se repete, mas afirmando que ela é contingente ao longo de um tempo mais ou menos extenso. Por isso, neste artigo, não retornarei a um passado conhecido, tentarei apenas deslindar os elementos cuja articulação me parecem compor o novo modelo da cidade latino-americana da forma como, no caso, ele se apresenta na Europa.

Por que este interesse pela noção de modelo? Sem dúvida porque permite escapar ao contexto hegemônico de mundialização para explicar um processo e porque seu reconhecimento permite em seguida antecipar o futuro e as possibilidades. Então, manteremos aqui a noção de modelo no sentido dado pelos economistas quando procuram saber quais são os elementos estruturadores de um sistema e as causas da reprodução ou não desse último. No entanto, tomo a escala espacial da cidade como substrato do modelo e não a escala nacional. As relações entre esses elementos deveriam permitir compreender a existência de modelos similares, mas também as modalidades de sua própria evolução histórica.

Saskia Sassen acredita poder reconhecer um modelo universal de cidade global que não se diferenciaria apenas porque seria - em muitos casos - truncado. 0 que seria apenas um retorno à hegemonia exercida por algumas cidades e pelas redes de todo tipo que exercem seus poderes virtuais a partir dessas cidades. Para um especialista, esse procedimento talvez fosse satisfatório. Para um pesquisador, ele me parece um pouco restritivo à medida que esse último considera que o tempo (político, histórico...) é uma contingência das hipóteses por ele levantadas. Em outros termos, propor a existência de um modelo de cidade latino-americana, ou europeia, talvez se deva ao fato de a década de 2000 ter vivido momentos políticos e econômicos muito diferentes. Durante os anos 1990, de abertura ao intercâmbio comercial, e também cultural e intelectual, as redes 
de especialistas viveram anos dourados. Essas redes fizeram circular, em todos os continentes, suas definições dos riscos e suas receitas. Pôde-se então denunciar uma "despolitização" das questões sociais e econômicas, criticando indiretamente os especialistas por dissipar as contradições não resolvidas, unicamente com base em sua credibilidade técnica.

Outros ressaltaram a complexidade e a dificuldade que representam para as populações urbanas, principais vítimas desses riscos de todo tipo, enfrentar a inflação das medidas burocráticas e/ou jurídicas, inspiradas pelas recomendações e receitas neoliberais. Mas pode-se também dizer que, em outro extremo, o trabalho dos pesquisadores, baseado nas contingências do tempo e da história, pode às vezes se mostrar como uma negação de todo impacto de um pensamento ou de uma ação reformadora, seja qual for.

\section{A procura de um modelo ou de um contexto espaço-temporal (por meio de tudo o que conhecemos como parte de nosso tempo)}

\section{Contemporaneidade dos acontecimentos políticos e econômicos na maior parte dos países da América Latina:}

Presença de governos nacional-populares, em seguida autoritários; depois democratização-descentralização.

ISI seguido de neoliberalismo econômico

\section{Anos 2000}

Circulação intensa das ideias através das redes no contexto da mundialização.

Diferenças das modalidades históricas entre a Europa e a América Latina que têm grandes efeitos nas sociedades: profundidade da crise na Europa, refundação nacionais na América Latina.

No contexto dos anos 1990 e 2000, o que temos então chamado a cidade neoliberal na América Latina? Como em todo lugar, mas talvez mais ainda que em outro, é a cidade financeirizada onde a construção sob todas as formas no conjunto do território urbano faz doravante parte dos ativos bancários, conduzindo por sua vez a privatização dos antigos serviços e a difusão de novos serviços quase exclusivamente privados. Essa definição se refere particularmente a todas as cidades da América Latina, grandes e médias, e mesmo às cidades tão diferentes quanto São Paulo ou Tegucigalpa.

Investigar os acontecimentos que pontuaram a história das cidades permite identificar as categorias do passado que esclarecem sobre as que estão em uso hoje e sobre os sistemas que organizam um domínio particular: no caso, a metrópole na América Latina. 


\section{Alguns paradigmas}

Neste texto, elenco quatro que foram todos temas de inúmeros trabalhos. ${ }^{1}$

Em primeiro lugar, pode-se notar, em todos os países da América Latina, a simultaneidade da mais forte explosão urbana do mundo, frequentemente qualificada como espontânea, informal e ilícita (acompanhada, aliás, por fenômenos de implosão urbana). Que interpretação socioeconômica se dava desse processo? Antes de tudo, foi uma explicação sociológica que pode ser lembrada nos seguintes termos: percebia-se a população "marginal" esperando poder conquistar o estatuto de proletário (ou assalariado), construindo seus territórios específicos que se tornarão rapidamente a expressão da extensão urbana mais forte do mundo (o spraw/ de hoje). Muitos sociólogos retrataram essa história (Duhau, 2012).

Com um pouco de recuo, pode-se pensar em duas explicações possíveis para a construção desse modelo espacial: uma remete à ausência de valor venal dos terrenos nas redondezas das cidades até uma época recente (os anos 1980) e a outra seria seu corolário, a indefinição prolongada no tempo do status da propriedade urbana. E vê-se então que os diferentes atores que ditam as regras dessa urbanização selvagem (fora de qualquer código de urbanismo) acabam por ter comportamentos muito parecidos nas diferentes cidades para contornar esses obstáculos. Veremos aliás mais adiante que o rápido aumento do valor fundiário e a passagem ao mercado, particularmente na Cidade do México e em São Paulo, constituem um dos paradigmas essenciais de nossa análise.
Há um segundo ponto que convém lembrar, pois condiciona profundamente as novas demandas e formas de gestão das sociedades urbanas na América Latina. Trata-se da rapidez da transição demográfica e o aumento da esperança de vida acompanhados do respectivo modelo. É preciso vinculá-los à urbanização? Uma nova leitura dos trabalhos dos anos 1990 nos incita a isso. Essa transição durou vinte e cinco anos (1960-1990), e a diferença de comportamento entre as zonas metropolitanas e as zonas rurais era então mais acentuada que a diferença entre os países. Desde 1980, segundo Maria Eugenia Cosio (Cosio, 1977), a média de filhos por mulher era inferior a 2,5. 0 que deixa supor que os imigrantes das zonas rurais mudavam seu modo de vida tão logo se instalavam em zonas urbanas. Os demógrafos - incluindo M. E. Cosio - atribuem a duas causas essenciais essa transição extremamente rápida que marca fundamentalmente as sociedades urbanas latino-americanas. Inicialmente, eles se referem à importância das políticas médicas das famílias pobres urbanas em relação à fecundidade. De fato, a multiplicação dos filhos por família deixaria de ser, desde os anos 1980, uma segurança para a sobrevida da família, mas, ao contrário, para enfrentar as dificuldades econômicas desses anos, as mulheres teriam sido levadas a um uso generalizado de anticoncepcionais, à disposição em condições de acesso fácil, sobretudo na cidade.

Essa mudança, acrescenta Cosio, acompanhou em todo lugar uma política de apoio à família urbana imaginada no México, mas que inspirou em todo subcontinente segundo modalidades bastante próximas e para a aplicação das quais a responsabilidade das mulheres é valorizada. Ao mesmo tempo, a esperança de 
vida aumentou em um ritmo igualmente rápido, fazendo aparecer uma sociedade urbana responsável por várias gerações.

Encontramo-nos então em um período em que os jovens (com menos de trinta anos) são ainda numerosos e os mais velhos (com mais de 60 anos) são hoje muitos. Essa estrutura demográfica pressupõe, ao mesmo tempo, uma mudança em relação ao trabalho, uma grande parte inativa da população e aposentadorias, baixas, não previstas ou inexistentes, além da função pública. 0 tradicional cuidado dos idosos pela família está hoje em crise, e esses últimos constituem uma nova demanda, assim como os jovens (estudantes, solteiros), para os poderes locais particularmente no que diz respeito à oferta de moradias. Qual é agora de fato o status de três gerações em relação ao crédito?

Em outras palavras, as condições demográficas de hoje não contradizem os pressupostos teóricos considerados universais, mas os colocam em uma perspectiva conjuntural com os desvios e as divergências em seus efeitos prováveis.

Há um terceiro paradigma, recorrente quando são evocadas as cidades da América Latina: o impacto das desigualdades sociais extremas existentes há décadas, que conduziram os centros de estudos do mercado a dividir a sociedade em cinco grandes "classes" $A, B, C$, $D, E$, que não correspondem mais aos esquemas marxistas do passado. Elas fundamentam atualmente as políticas urbanas, particularmente a política de habitação. Estereotipadas por gabinetes que atuam em nível nacional ou internacional, elas são substituídas às antigas categorias de assalariados, de "marginais" e mesmo àquelas que surgiram mais tarde, de pobres e ricos. Em relação a essas antigas categorias, elas dão uma visão asseptizada da sociedade transformada em um aglomerado de consumidores, sintetizando em uma letra apenas a diversidade dos status profissionais, dos ofícios, das atividades e das condições sociais. Assim, elas parecem aceitas como "dados fixos", inquestionáveis. "Eu pertenço à classe D", especifica um comerciário; isso deveria bastar para explicar ao interlocutor seu modo de vida e mais ainda seu comportamento. Mas essas categorias se tornaram ao mesmo tempo um instrumento técnico de urbanismo, comum aos arquitetos, promotores e gestores, pois 0 recurso a sua existência condiciona muito as intervenções no espaço urbano em construção ou em transformação, tanto do ponto de vista das infraestruturas como dos serviços e da moradia. Principalmente, elas revelam o futuro possível de um bairro, pois traduzem a capacidade de seus habitantes de pagar impostos, mas ainda mais de obter crédito. ${ }^{2} 0$ que remete a uma definição de um modelo de cidade "latino-americana" hoje "financeirizada", suportado por um valor fundiário urbano em aumento muito rápido. Ao mesmo tempo, esses aumentos dos preços obrigam as diferentes categorias da população a modificar suas estratégias tradicionais de acesso à moradia e à ocupação, e a entrar na batalha do mercado. Assim, os empreendedores, assim como as organizações populares, com certeza munidos de "armas" diferentes, são obrigados a entrar no que alguns chamam de caça aos espaços". ${ }^{3}$

Há dois tipos de resposta a esse dilema por parte das populações as mais modestas que condicionam a reprodução do modelo espacial centro/periferia tradicionalmente aplicado nos espaços metropolitanos 
latino-americanos, suavizada pelas opiniões de autores que preferem falar de fragmentação em vez de segregação. É então o modelo "multicentralidades/periferias". Os dois tipos de resposta, mesmo se expressos de modo diferentes, estão presentes em inúmeras cidades grandes da América Latina. A primeira é a aceitação do afastamento dos centros das cidades, que são, no entanto, os espaços provedores de atividades de qualquer nível de qualificação, de atividades precárias, de atividades noturnas. E isso, com o risco de acumular as horas em todos os tipos de transporte público ou privado e de precisar inventar novos modos de vida. A segunda é a invenção de formas de pressão sobre os poderes locais para que seja facilitado o acesso à moradia por meio de um crédito adequado ou para que reconheçam o direito de as pessoas permanecerem no lugar onde estão. Essas formas de pressão podem se exercer tanto na rua quanto no interior das instituições de participação. Teoricamente implementadas em quase toda a América Latina, de acordo com um esquema inspirado nas experiências de governos municipal do PT brasileiro, o modelo da cidade latino-americana "participativa" rodou o mundo e inspirou tanto os poderes locais quanto as organizações internacionais quando elas enumeram as condições da democracia ou da sustainable city.

0 primeiro tipo de resposta, a aceitação do afastamento, remete à extrema dificuldade que, de fato, vivem os poderes públicos para dar uma coerência às políticas de transporte ou a regular aquelas atualmente em vigor. Sem dúvida, trata-se de um dos traços marcantes do modelo latino-americano há longos anos e um dos mais explosivos da última década. Ora, pode-se notar que o problema dos transportes está ausente do discurso dos prefeitos, embora quase sempre de esquerda ou pelo menos abertos à participação, enquanto ele ocupa um lugar constante naquela da sociedade urbana, consideradas todas as classes. Por outro lado, as instituições municipais parecem estar comprimidas entre a inextricável confusão que reina no antigo setor privado e nos serviços mais recentemente privatizado e um setor público, às vezes presente, mas suplantado pela urgência.

\section{Cidade caótica ou cidade neoliberal?}

Se até os anos 1960 os arquitetos detinham um quase monopólio da reflexão sobre o urbanismo e as cidades, o crescimento desenfreado destes últimos anos, tanto em extensão quanto em população, contribuiu para que isso mudasse. Visto inicialmente como uma vitrine da modernização - uma visão que a época autoritária se esforçou por tornar oficial por duas décadas - esse crescimento se transformou pouco a pouco em crise, em pesadelo até, que culminou nos anos 1980. Uma crise no entanto tão difícil de assimilar que as cidades da América Latina fazem parte, nos anos 2000, deste Planet of Slums, um título impactante que transformou então o livro de Mikes Davis em best-seller. Aliás, as estatísticas internacionais, que associam sempre implicitamente pobreza e violência, apresentam algumas das cidades da América Latina como as mais violentas do mundo.

No entanto, trata-se de um atalho enganador. A questão merece ser colocada de outra 
maneira. Os paradigmas que levantamos na primeira parte deste texto, que são a essência do neoliberalismo, misturados a diversas histórias, não deixam de se interrogar sobre a continuidade de experiências comuns em todo o continente e no tempo, às vezes com alguns anos ou década de atraso.

Do ponto de vista local, a coincidência principal está em uma certa similaridade do discurso político sustentado por poderes locais, cuja fibra social frequentemente antecede a dos governos nacionais, mas que já vivem em alternâncias políticas. Eles são o reflexo de atitudes de classes médias que não são mais impregnadas pela análise radical dos intelectuais orgânicos dos anos 1990. São os poderes locais que procuram inspirações urbanísticas e sociais, na diversidade das medidas sociais/ técnicas propostas pelos fóruns internacionais. Eles reconhecem a similaridade dos problemas apresentados em toda a América Latina. São aliás frequentemente percebidos como os únicos portadores de um discurso hoje de esquerda no mundo e crítico de um neoliberalismo aplicado à gestão do território urbano.

No entanto, o custo social das doutrinas neoliberais que se multiplicaram após o consensus de Washington, adotadas pelos sucessores dos governos autoritários que se seguiram às ditaduras, parecem ter deixado se espalhar em todo lugar uma certa desconfiança em relação à classe política local ou mesmo nacional.

Do lado da sociedade urbana, a "informalidade" no trabalho e nas atividades muda de sentido. Designa hoje um fenômeno que se estende da precariedade à transgressão (Telles, Gilgia, Azaïs, 2012) e não é apenas a eventual "desindustrialização precoce" dos países segundo a expressão já adotada pelos economistas e, por conseguinte, das cidades onde as formas de salariado tradicional estagnam, que é a causa. Poder-se-ia até dizer que, ao se aproximar das características dos empregos informais e ao transgredir de maneira complexa o direito do trabalho, os empregos formais se "informalizam" (Salama, 2013).

Isso seria dizer que esse modelo urbano do período atual poderia ainda se explicar por meio de duas teses que foram muito propagadas nos anos 1960-1980 e que, uma e outra, faziam do Estado o principal ator do debate porque ele não desempenhava seu papel. A tese de Manuel Castells, muito difundida então na América Latina, via o Estado antes de tudo como a expressão e a imposição dos interesses de classe, uma tese hoje suplantada, por ele mesmo, aliás. A tese de O'Donnell explicava as experiências autoritárias da época como uma alternativa à incapacidade de os governantes aprofundarem o que poderia dinamizar o processo de industrialização (pós ISI). Ela também foi suplantada mesmo quando se procura ainda refundar o Estado e a nação. É então na análise comparada das experiências urbanas que se deve continuar a procurar um modelo latino-americano a se transformar o tempo todo, situando-se em uma escala e em um grau de precisão que dá sentido à figura abstrata de um eventual modelo.

\section{Conclusão}

0 resumo de uma experiência de pesquisa feita em São Paulo e na Cidade do México servirá como conclusão (Rivière d'Arc, 2014; Menna Barreto, 2014). Tratava-se da comparação entre as diferentes formas de acesso à moradia em 
um contexto de grande aumento do valor venal urbano. Apoiava-se na constatação comum a ambas as cidades, de uma extensão urbana extremamente grande (sprawl ou espalhamento) apesar da diminuição do crescimento da população. Essa constatação revelava uma das necessidades mais imperativas da sociedade: a moradia. Eis então a pergunta que se coloca para as áreas metropolitanas: como administrar e/ou interromper essa extensão ao mesmo tempo que se atende às necessidades residenciais mais urgentes sem que elas sejam devoradoras de espaços.

Na Cidade do México, nos anos 2000, sob os governos de Andres Manuel Lopez Obrador e de seus sucessores, para tentar restringir a extensão espacial em um espaço administrativo dado, o DF, foi estabelecido um programa que não durou muito tempo, mas que teve consequências imediatas e teve objeções de inúmeros atores, o Bando 2. Esse programa pretendia interditar a promoção de novos conjuntos residenciais no segundo perímetro em relação ao centro histórico, quer dizer no Bando 2, a fim de concentrar os investimentos e de dar um impulso concreto à requalificação do centro histórico degradado e mesmo despovoado. Mas quais eram os meios de pressão do governo municipal sobre as construtoras, que, por sua vez, se beneficiaram com um processo de transferência da promoção da moradia do setor privado, para os quais elas investem exclusivamente no centro da cidade onde os preços fundiários originaram um crescimento considerável? Bem fracos. As consequências desse programa foram então a imigração das operações de moradia para além do Bando 2, em municípios do estado do México, muito satisfeitos de se responsabilizar pelas infraestruturas e suscetíveis de se tornarem contribuintes.

Esse resultado bastante próximo, parece, da situação de Madri antes da crise, ${ }^{4}$ contribuiu além disso para a extensão urbana e para a construção de loteamentos muito distantes das zonas de atividades do DF. Em suma, uma situação que, do ponto de vista social e do relato de sua vida cotidiana dos habitantes, se parece àquela de inúmeras cidades da América Latina e de São Paulo entre elas. Pode-se destacar que um dos pontos-chave do debate hoje é a grande distância do local e das possibilidades de trabalho.

Inversamente, em São Paulo a municipalidade não se pronunciou de maneira autoritária, mas tentou promover os investimentos no espaço urbanizado. Contrariamente ao que aconteceu na Zona Metropolitana da Cidade do México, a "bolha imobiliária" para os imóveis de alto padrão atingiu o pico no início dos anos 2000. As empresas que trabalhavam para a categoria de alto padrão se voltaram então para as classes médias $C$ e $D$, segundo um modelo residencial padrão e de baixo custo. A diversidade dos programas propostos pelo governo central, através da Caixa Econômica, Ihes permitiu essa reconversão. Elas ocupam além disso espaços disponibilizados pela demolição das zonas industriais. E, para praticar sua reconversão, recorrem à prática seguinte: construir segundo as oportunidades seja na zona metropolitana, seja no território municipal, deixando à cidade o cuidado de resolver o problema da moradia dos trabalhadores com "menos de cinco salários mínimos", ou seja a classe $D$, isto é, investimentos a fundo perdido.

Ora, apesar das diferenças e do interesse que os empreendedores paulistas mostraram 
no início da experiência mexicana (Construção modelo popular, 2007), encontra-se hoje, aqui e ali, diante de um preço fundiário que aumenta rapidamente mesmo que de maneira desigual de acordo com os espaços. No DF, é por não haver muita oferta; no município de São Paulo, porque os espaços eventualmente disponíveis e minuciosamente disputados são requalificados para a moradia de uma população que pode pagar.

Diante dessa financeirização dos espaços urbanos, estratégias e ações dos habitantes ou dos pretendentes à cidade mudaram, tanto na Cidade do México quanto em São Paulo. A ocupação ou a invasão de know-how tradicional que caracterizou mais de um século de urbanização, tanto aqui, como lá, não são mais a forma de ação dominante. Na Cidade do México, a reivindicação dominante e o tema de mobilização mais forte são o do acesso a um crédito apropriado à situação do devedor. Outra maneira, compatível com a primeira, é a adesão a uma associação cujo líder se incumbe de levar a solicitação ao INVI (Instituto Nacional de la Vivienda), ou diretamente junto à prefeitura, impedindo assim a participação, mesmo se a prática dessa última esteja afirmada pelo prefeito da Cidade do México, que alega se inspirar no Estatuto da Cidade Brasileira no discurso que pronunciou quando foi assinada La Carta de la Ciudad de México por el Derecho a Ciudad, em 13 de junho de 2010.

Em São Paulo, O Movimento escolheu três modalidades de ação. ${ }^{5}$ Seus membros eleitos participam do Conselho Municipal de Habitação com seus aliados das ONG, mas o orçamento destinado à moradia, examinado por esse conselho, é extremamente baixo diante das necessidades. Além disso, ele procura terrenos que possam ser construídos ou reabilitados por razões diversas, ${ }^{6}$ que ocupa simbolicamente, enquanto pressiona a prefeitura para que faça valer o direito de preferência ou os adquire a preço baixo.

Então, diferentes estratégias, mas pontos comuns: a financeirização da cidade abalou as estratégias tradicionais cujo corolário era o status fluído da propriedade em direção a ações totalmente integradas ao mercado. Há então ainda a simultaneidade de mudanças marcantes nas duas cidades. Aqui e lá, além disso, percebe-se a importância do papel atribuído no debate às corporações e aos meios profissionais. 0 que permite fazer a seguinte observação: a consideração das desigualdades sociais extremas, como elemento estruturante dos projetos de urbanismo como "dados sociais fixos", levou os profissionais aqui e lá à realização prática de modelos arquiteturais muito próximos. A aplicação desses modelos traduz uma mesma combinação de dados, 0 custo da construção, o mais baixo possível para contrabalançar o preço fundiário; e se surge finalmente uma espécie de consenso em torno de um modelo único de pequenas casas e apartamentos (em torno de $40 \mathrm{~m}^{2}$ )... ${ }^{7}$

Logo um modelo espacial, cujo caminho de leitura sociológica e geográfica é muito próximo. Assim se construiu a cidade latino-americana neoliberal. Ela está no entanto já - atualmente em uma nova fase. A de uma tomada de consciência sobre o plano político e responsável por alguns desse neoliberalismo: a escolha unilateral da prioridade dada ao carro particular fomentado pelo crédito fácil, enquanto, ao mesmo tempo, privatizavam-se os serviços; uma ética política que parece frequentemente se satisfazer apenas com o sucesso de 
suas elites, apesar de uma redução geral das desigualdades e da pobreza na maior parte dos países. ${ }^{8}$ Em contrapartida, as reuniões e os fóruns frequentados pelos membros das redes profissionais latino-americanas (verdadeiras virtual communities latino-americanas), ocorrem de maneira quase ininterrupta sobre a maneira como cuidar da cidade. E isso, em um momento em que o papel do Estado é levado ao cerne das cenas latino-americanas e quando certas políticas urbanas, adotadas pelos poderes locais mais aqui do que ali - em Bogotá ou Medelín por exemplo, surgem já como a antecipação de um modelo ativo e "actante" para as cidades do continente.

\section{Hélène Rivière d'Arc}

Institut des Hautes Etudes de l'Amérique Latine. Centre de Recherche et de Documentation sur les Amériques. Paris, França.

helene.riviere_d_arc@sfr.fr

\section{Notas}

(1) Não é possível enumerar todos os trabalhos que permitem apresentá-los.

(2) Podemos então perguntar por que as metrópoles da América Latina não vivenciaram a crise como Cleveland ou Madri; talvez isso se deve à prudência dos promotores e banqueiros, não ainda persuadidos de que a maioria da população urbana já se tornou de "classe média", ou antes D+ ou C.

(3) É com esta metáfora que um dos líderes da União dos Movimentos de São Paulo resume a tática de entrada das organizações populares no mercado fundiário.

(4) Mesmo se não se falou de bolha na Cidade do México.

(5) Entrevista do autor com os líderes do Movimento $(2009,2010)$.

(6) Em geral, antigos terrenos industriais e/ou terrenos abandonados.

(7) Anedota: a viagem dos empreendedores de São Paulo no Estado do México em 2009, para compreender como era possível construir loteamentos tão grandes de casas tão baratas (Ecatepec, Cuautitlan).

(8) Afirmação sob reservas. 


\section{Referências}

AZAïS, C. e STECK, J. F. (2011). Les territoires de l'informel. Espaces et Sociétés, n. 143.

CASTELLS, M. (1972). La question urbaine. Paris, Maspero.

COSIO ZAVALA, M. E. (1997). Changements démographiques en Amérique latine. Cahiers des Amériques latines, n. 22.

DAVIS, M. (2006). Planet of Slums. Londres/Nova York: Verso.

DUHAU, E. (2012). La sociologie urbaine et les métropoles latino-américaines. Sociologies, Dossier Actualité de la sociologie urbaine dans des pays francophones et non anglophones. Disponível em: http://sociologies.revues.org/4164.

DUHAU, E. e DUHAU A. G. (2008). Las reglas del desorden. Habitar la metrópoli. Mexico, Siglo XXI.

MENNA BARRETO, H. e MIGNAQUI, I. (2014). "Interventions publiques, financement et production du logement, comparaison São Paulo et Buenos Aires". In: AZAÏS, C. e LEHALLEUR, M. P. La gouvernance dans quatre métropoles d'Amérique latine. Berna/Bruxelas, Peter Lang (no prelo.)

O'DONNELL, G. (1979). "Tensions in the bureaucratic authoritarian state and the question of democracy". In: COLLIER, D. (ed.). The new authoritarism in Latin America. Princeton-NJ, Princeton University Press.

RIVIERE D'ARC, H. e SCHNEIER, G. (1993). “De Caracas à Rio et Buenos Aires: un siècle d'aspiration à la modernité urbaine". In: RIVIERE D'ARC, H. (dir.). L'Amérique du Sud au XIXe et XXe siècles, héritages et territoires. Paris, Armand Colin.

RIVIÈRE D'ARC, H. (2012). "Savoir-faire no acesso ilegal/informal à habitação na cidade do México e em São Paulo". In : AZAÏS, C.; KESSLER, G. e TELLES, V. da S. Ilegalismos, cidade e política. Belo Horizonte, Traço.

(2014). "São Paulo et Mexico, 'chasse aux espaces' ou nouvelle dictature du foncier urbain". In: AZAÏS, C. e LEHALLEUR, M. P. (dirs.). La gouvernance dans quatre métropoles d'Amérique latine. Berna/Bruxelas, Peter Lang (no prelo.)

SALAMA, P. (2012). Les économies émergentes latino-américaines, entre cigales et fourmis. Paris, Armand Colin.

SASSEN, S. (1991). The Global Cities: London, Tokyo, New York. Princeton-NJ, Princeton University Press.

TELLES, V. da S. (2012). "Jogos de poder nas dobras do legal e do ilegal; anotações de um percurso de pesquisa". In: AZAÏS, C.; KESSLER, G. e TELLES, V. da S. Ilegalismos, cidade e política. Belo Horizonte, Traço.

Texto recebido em 10/nov/2013

Texto aprovado em 15/dez/2013 
